\title{
Anxiety in Visually Impaired Students about the Future
}

\author{
Aydın Kızılaslan', M. Meral Kızılaslan² \\ ${ }^{1}$ Department of Education, Ibrahim Cecen University, Turkey \\ ${ }^{2}$ Department of Education, Ataturk University, Turkey
}

\begin{tabular}{l}
\hline Article Info \\
\hline Article history: \\
Received May 16, 2018 \\
Revised May 27, 2018 \\
Accepted May 31, 2018 \\
\hline
\end{tabular}

Keyword:

Anxiety

Case study

Interview

Visually impairment students

\begin{abstract}
The aim of this study was to determine the anxiety level that visually impaired students may have for the future when planning their profession. Anxiety is defined as excessive level fear and worry about real or imaginary situations. So the excessive worry can affect the ability to act to solve a problem. This study was a case study based on the semi-structured interviews. The study group consists of six 8th grade students with visual impairment. The aim of selecting students with visual impairment as a sample group is to determine the individuals who are aware that education is an important for their future plans but at the same time aware that the barriers created by society have greater impact on the socialization. As a result, visually impaired individuals are willing to be part of the society, but the created obstacles cause anxiety in many different ways as they constitute their futures. This situation negatively affects their motivation and academic performance, and diminishes the importance of education for them as well.
\end{abstract}

Copyright (C) 2018 Institute of Advanced Engineering and Science. All rights reserved.

\section{Corresponding Author:}

Aydın Kizılaslan, Department of Education, Agri Ibrahim Cecen University, Erzurum Yolu 5. Km, 04000 Ağrı Merkez/Ağrı, Turkey. Email: ydnkizilaslan@gmail.com

\section{INTRODUCTION}

Although it varies from country to country, individuals with visual impairment (VI) are commonly defined in two different ways: legal and educational. After all corrective adjustments, people with visual acuity of $1 / 10$ or $20 / 200$ or less than this, in other words those cannot see more than 20 degree of visual field are defined as legally blind. Besides that after all corrective adjustment, those have visual acuity between 20/70 and 20/200 are defined as individuals with low vision. An educational definition proposes that those need the braille-tactile alphabet (Braille Alphabet), or uses of auditory materials are referred as educational blind [1-2].

There are differences in characteristics of students with VI such as functional views, socioeconomic status, cultural backgrounds, age at onset of vision loss, the presence of other disabilities, and cognitive competence. Besides that, while these individuals present common characteristics as their normal peers in terms of their mental functions, they can experience some limitations in the areas of psychomotor, conceptual learning, and language development due to lack of vision. So the effect of VI on the development of a child depends on the severity, the type of loss, and onset of impairment [3-4].

The feelings of being dependent on another person and social barriers are the leading factors that negatively affect the mental health of individuals and cause psychological and behavioral dysfunction. Mental illness or mental distress or the manifestation of behaviors and experiences are referred as psychopathological disorders [5-8]. Psychopathological situations that can be experienced by the students with impairment due to disability can negatively affect their academic achievements, their attention level in a lesson and their motivation towards the lesson [9] .For this reason, teachers should be informed about the 
psychopathological conditions (emotional and behavioral disorders, abnormal/incompatible behavior, and mental depression) that students with VI are likely to experience.

For instance age-related macular degeneration (AMD) that cause deterioration in retina affects the patient's central vision progresses and leads to a loss of vision in one or both eyes. As AMD progresses, a blurred area near the center of vision is becoming common symptom. Over time, the blurred area may grow larger or blank spots may develop. Objects also may not appear to be as bright as they used to be [10]. Shock, disbelief, depression, and anger are common reactions among people who are diagnosed with AMD. 30\% of individuals with this type of disease often experience depression [11]. Hallucination syndromes can be diagnosed at these individuals by increasing of the visual loss. Although these hallucinations are harmless, they may lead to emotional disorders. For example at first, students who clearly see what is written on the board may experience a dilemma after a while whether what he sees correct or not [12].

Situations that do not cause any anxiety for individuals beforehand have the potential to cause anxiety after vision loss [13]. Dense streets, crowded rooms, noisy corridors, complex instructional materials initially lead to the creation of tremendous fear reactions. These fears are ultimately accompanied by feelings of anxiety [14-16]. In addition, students with low vision may experience various negative stress emotions depending on the severity of visual impairment in the classroom. Providing an educational environment and training materials that enhance the tactile or auditory experience is the best way to overcome this situation in the classroom.

Anxiety is a feeling of fear, worry, or unease. When worrying becomes excessive, it can lead to anxiety, panic and even cause illness. Anxiety disorder is strongly affects students with VI. Anxiety is described as a sense of uneasiness, nervousness, worry, fear when faced with danger, threat, or stress [17]. Job loss, relationship breakdown, serious illness, major accident and grief can be main source of anxiety [1819]. Furthermore the roles and basic and diverse responsibilities of the individuals' associated with the future, the job and also work-related fears are another source of anxiety [20-22].

Empirical evidence has shown that students with VI engage less in the learning process because they face a range of anxiety responses compared with their peers [23]. With anxiety, individuals cannot focus on the future. So this situation has potential to lead the appearance of panic which is the one of the subcomponents of anxiety in children with VI. Also, not being able to control emotional state and the belief that something went wrong causes 'anger seizures'. The anxiety of correct reading and writing during exams leads to 'lack of stability', which is another of the sub-components of tension and irritability during the exams [24]. Being highly sensitive about the perception that something is misunderstood on the exam leads to reading again and leads to 'lack of self-confidence', another sub-component of anxiety. Perhaps giving enough time to students with VI in this regard may increase their motivation by reducing emotional tension [25-27]. In addition low self-esteem and high levels of anxiety cause a decrease of social and family relationships [28-29].

Future anxiety is another kind of anxiety. Zaleski defined it as "a state of apprehension, fear, uncertainty and fear of undesired changes expected to occur in the future, and there may be a threat that something unreal is going to happen to the individual when he/she is extremely anxious about the future" [30]. The lack of self-confidence, the weakness of self-competence and uncertainty about an unpredictable future threat disrupts ability to avoid it or to mitigate its negative impact, and thus results in future anxiety [19].

Education is the most important driving force for better future or better life. Education, not only contributes to the socialization and acculturalization of individuals by transferring the knowledge, value and skills of the society to new generations but also it is also linked to better physical and mental health, fewer crimes, less incarceration, good life standards [31-33]. Therefore, it is very important for VI individuals to possess a profession that is appropriate in their interests and abilities through education. Literature reviews show that there are very few studies have been conducted on the anxiety of the visually impaired individuals about the future plans and expectations for their professional life. This study aimed to examine the anxiety of the visually impaired students about future expectations and the actualization of these expectations.

\section{RESEARCH METHOD}

This qualitative study focuses on a deep understanding of anxiety disease of the VI students. Qualitative research is designed to reveal thoughts and feelings of research participants in a focused way in order to examine the lived experiences [34]. The purpose of the phenomenological research that was used as method of this study was to analyze anxiety in VI students about the future within the context of a phenomenology. To determine student's anxiety about future and to access the depth of their emotions and thoughts semi-structured interview form was used as data collection tool [35]. Furthermore, attention has been paid to noise pollution. Once participants provided their informed consent, an interview was conducted 
with each participant in a private room to ensure confidentiality. In-depth questions were used to determine to elicit a vivid picture of the participant's perspective about research question. Expert feedback and suggestions were also solicited for the questions and they are revised accordingly.

The data obtained through the interviews were analyzed using descriptive analysis procedure . "Descriptive analysis characterizes the world or a phenomenon-answering questions about who, what, where, when, and to what extent. Whether the goal is to identify and describe trends and variation in populations, create new measures of key phenomena, or describe samples in studies aimed at identifying causal effects, description plays a critical role in the scientific process in general and education research in particular" [36]. Interview data consist of tape recordings, typed transcripts of tape recordings, and the interviewer's notes. Typed transcripts are the most utilized form of interview data. During the data analysis phase of the research, after data collection, transcripts are coded according to participant responses to each question and/or to the most salient themes emerging across the set of interviews. However, codes were not formed on the grounds that a small number of students participated in the study and that students did not answer all the questions of the interview form. So the answers given by students to each question were analyzed descriptively.

\subsection{Study Group}

Participants of this study consist of two blind students and the others have low vision. As can be seen in Table 1, one of these students is female and the others are male. The female student is blind. All students are studying in the 8th grade of the school of VI. As the health certificate about the students was not reached from the first hand, the information about the students' vision acuity was attained at the interviews. Students have no additional disabilities.

Table 1. Participant of the study

\begin{tabular}{cccc}
\hline Student Code & Visual Acuity & Gender & Level of impairment \\
\hline $\mathrm{S}_{1}$ & Low vision & Male & One eye \\
$\mathrm{S}_{2}$ & Blind & Male & Totally \\
$\mathrm{S}_{3}$ & Low vision & Male & Both eyes \\
$\mathrm{S}_{4}$ & Low vision & Male & Both eyes \\
$\mathrm{S}_{5}$ & Blind & Female & Totally \\
$\mathrm{S}_{6}$ & Low vision & Male & One eye \\
\hline
\end{tabular}

\section{RESULTS AND DISCUSSION}

In this section, the results of the interviews based on the research questions were analyzed. The answer of the students related to the question "What is your the expectation from the school?" shows that school is chance for students VI facilitating the self-actualization or a way to build their own future.

"...School has the opportunity through education to pursue my dreams." (S1)

"...School is inspiring me to achieve my goals and help me to feel better. It gives me the belief that I can do something." (S2)

"...I want someone to accept me like this. School is a fact of life, and getting an education can help me build the kind of future life I want." (S4)

"... Without school, I cannot build my own future. I have to be well-educated to do enormous things." (S5)

The answers given by the students to the question "Which profession do you want to study in the future?" show that they do not care much about the barriers that community built for them. The answers are generally related to their daily experiences.

“...I want to study social studies. I like social lessons very much; actually I love all my lessons. I want to be social studies teacher because the content of these lessons is very enjoyable." (S1)

"...I want to be police officer. For example, when an injustice is done to one person, everyone else has to wonder what it would take for that same injustice to be done to me." (S3)

"...I want to be a doctor. In my case people can see better."(S6)

Answer of the question "What profession do you plan to have??" shows that students are not aware about requirement of the professions that they want to have

"...I have to work hard. We have to study my lessons very much and so on." (S1)

"... The only thing I know is to overcome the obstacles people are built. I have to work hard to good profession.” (S3)

"...I never thought that what profession I should have. My family insists me to continue my education. Now, I am working in my lessons. I do not know what else I have to do."(S5)

"...I just want to have profession that I can feel myself comfortable." (S6)

IJERE Vol. 7, No. 2, June 2018: $152-158$ 
Students' answer about question "Are you self-confident enough to carry out your future plans?" show that most of the students are idealistic about their future plans

"...I believe that I have as much self-confidence as I am. This self-confidence helps me to feel comfortable. I believe in myself that I can accomplish almost everything. Self-confidence is what motivates us for everything." (S1)

"...Yes, because I know I can overcome the requirements of the profession that I like more. But sometimes I feel that I cannot do it very well because I cannot see very well." (S2)

"...If I do not believe in the importance of the education, I will not continue to study. My parents live in city far from here. Because the school for the visually impaired is only located in this city. If I do not believe in being successful, why do I come and study here away from my family? It is important for me to continue the study, but my father says that you cannot be successful and prepare yourself for this situation but it does not matter for me. I trust myself." (S3)

“...I cannot see very well, so I'm pessimistic a bit about this as well. I'm worried." (S4)

It is understood that students who have VI are worried about the future when we ask the question "Do you think that your impairment may affect your future plans?"

"...No, I do not think that my plan will change. People must be able to do what they believe. I believe I can become a teacher." (S1)

"...I don't think so. Because it does not mean that a person with visual impairment, hearing impairment or physical impairment are not capable of doing anything. I also have the features that I need to have in order to be a lawyer. In other words, a person must be able to believe in his/her abilities." (S2)

"...I think we have to go after what we believe. Even if there is no one support us." (S3)

Students with visual impairment sometimes want to share their future plans with their families or with their peers and the answers they receive from individuals can affect their idea. To get students' ideas on this case following questions asked: "With whom do you share plans for the future?" And "What kind of response do you get?"

“...My friends, my teacher, my family ... They give positive feedback. For example when I talked with family about my career, my mother says that I trust you and I will always support you. They support and respect my ideas." (S2)

"...In general, I do not share my ideas with anyone. Because I fear that those people will oppose me. But sometimes I share my ideas with my family, but my relatives mmm never. Because many of these people do not trust me." (S5)

"...My brother, my mother, my father, my school friends. My family supports me about my future plans. My brother supports me a lot. Generally everyone is trying to give me advices." (S6)

In order to determine the effect of frustrations on anxiety level, the students were asked: "Do you sometimes find yourself feeling disappointed with education and friendships successful? ". According to the answers given, the students' failures in daily life lead to increase in anxiety level about the future.

"...Sometimes when I talk with my school friends. In some cases, I experience frustrations." (S1)

“...For example, when my teacher sometimes yells at me in classroom, my motivation falls. As you know I cannot see my teacher's face when I think that my teacher is mad me." (S3)

"...It happens at school much. I feel disappointed when my parents do not let me to go out. When I go out alone, my friends do not play the game with me. In the meantime I forgot to say that I get disappointed much when I cannot do exam questions." (S6)

The question about "What is pessimism for you?" was asked to find out the most pessimistic situation for students with VI. According to answers students' disabilities are not reason to be pessimistic, but accepting individuals with disabilities as obstacles in society is the main source of their pessimism.

"...It is pointless for me to be pessimistic." (S2)

"...Having a distrust of people is the most pessimistic situation for me. For example one of our friends played the instrument very well, but he did not accepted at fine arts school because of his the visual impairment." (S4)

"...People always talk with me about my blindness. This is scaring me for the my future plan." (S5)

The most pessimistic situations of students with VI are important in that we could determine the stress and anxiety level of students that they may have in the future. In this respect, the question about "What is the optimistic situation about future?" was asked to identify their fear about future. The students gave the following answers to this question. 
“...The most hopeful situation for me is to complete my education." (S1)

"....The most hopeful thing is for me to have a good profession." (S2)

"....Not being in need of people can be the most promising thing for me." (S3)

"...I do not want people to treat me like a monster." (S4)

"....the future is mysterious for me now." (S5)

"...I want to be a doctor and heal people." (S6)

Especially economic plans are at the forefront when we ask visually impaired students about their most important plans for the future.

"...Now our parents are interested in our needs, and I would like to take care of my family's economic needs in the future." (S1)

"...My future expectation is to be self-sufficient individual in every sense." (S2)

“...Making money, having a job.” (S5)

Visual difficulties may influence in physical, mental, social, educational and vocational aspects. Visual impairment individuals have to deal not only with the difficulties of his/her physical impairment but also with the psychological and behavioural problems specifically during adolescence [37]. Social and physical isolation also creates problem of anxiety and depression. In turn, anxiety and other septoms related anxiety may cause a further decline in quality of life, may aggravate disability caused by the visual impairment [38]. Visual impairment may have a substantial impact on various life domains such as interpersonal relations, mobility, work, mental well-being. As it is known the economic impact of vision loss is also substantial. It is necessary to make plans for the future by knowing the competence of the person. However, students with visual impairment are not planning a future that is appropriate for their visual disability. They usually do not care about their visual disability while planning their future, choosing the profession. Students with visual impairments need an education program options to meet their future plans. Visually impaired students have indicated that they are continuing to school in order to make better plans for the future. It is also understood that they think there will be no plans for the future without schooling. This shows that students with VI are planning their future like as their peers. It is also understood that they are not aware of the requirements this profession when choosing a profession. They also state that they are aware of their disappointment. This suggests that although students are idealistic, they have concerns about the future due to their disability. Although the students who are aware of their VI have worries and indecisiveness about the future, it is determined that their self-confidence is at the upper level. They think that their vision deficits will not change their plans for the future. Future means hope and concern for them.

One of the situations in which individuals feel isolated is frustration. But the frustration is the negative aspect of the negative externalities. People without disability can quickly get out of situations that cause frustration. However, an individual with VI is generally frustrated during a lifetime. Although this may seem familiar to individuals with visual impairment, frustration is causing anxiety in their lives. When students are disappointed in situations such as proving themselves, identity formation, or any disruption to their future plans, it has been determined that these frustrations are the source of their anxiety.

Individuals with visual impairment may be pessimistic because of the negativity experiences throughout their lives. Sometimes they can look positive, regardless of any of the negativities. But despite these students do not develop a pessimistic picture of the future. Employment of individuals with visual impairment has the lowest rate among people with disabilities in Turkey. So it can be predicted how difficult it will be for the visually impaired individuals to be part of community as an economic entity.

It is the manifestation of the existence of a problematic that the individuals with visual impairment are expected to have great expectations about the future. As a result, concerns about the future arise. Their presence in the irrational expectations of the future can be a sign of the quality of referral services for them [39]. Disability employment regulations can be one of the simplest steps that can be taken to minimize the future anxiety of the visually impaired individuals. The scope of the education given for visually impaired individuals to develop in the direction of their qualifications can be expanded. In this direction, the interests, skills and competences of visually impaired individuals should be assessed realistically. Vocational guidance activities should be carried out in a more rigorous order even without interruption. On the other hand, guidance and psychological counseling services for visually impaired individuals should be carried out with care.

\section{CONCLUSION}

As a result compared to their peers, students with visual impairments are at a higher risk for depression, anxiety, and other psychological problems. Unemployment is another major risk factor for depression. By reducing barriers towards entering the labour market for people with VI and by enhanching education quality, prevalence of anxiety among the students with VI can be reduced.

IJERE Vol. 7, No. 2, June 2018: $152-158$ 


\section{REFERENCES}

[1] American Foundation for the Blind [AFB]. (2000). Optical character recognition systems. Retrieved February 22, 2018 from the World Wide Web: http://www.afb.org/info document view.asp?documentid=1283

[2] Lewis, S., \& Allman, C.B. (2000). Seeing eye to eye: An administrator's guide to students with low vision. New York: American Foundation for the Blind.

[3] Levack, N., \& Loumiet, R. (1993). Independent living series - A curriculum with adaptations for students with visual impairments. Texas School for the Blind and Visually Impaired.

[4] Papadopoulos, K., Metsiou, K., \& Agaliotis, I. (2007). Adaptive behavior of children and adolescents with visual impairments. Research in Developmental Disabilities, 32(3), 1086-96. doi: 10.1016/j.ridd.2011.01.021

[5] Alexander, L., \& Martray, C. (1989). The development of an abbreviated version of the mathematics anxiety rating scale. Measurement and Evaluation in Counseling and Development, 22, 143-150.

[6] Baker, S., Heinrichs, N., Kim, H., \& Hofmann, S. (2002). The Liebowitz Social anxiety scale as aself-report instrument: a preliminary psychometric analysis. Behavior Research and Therapy, 40, 701-715.

[7] Pallero, R. (2008). Psychosocial adjustment to visual impairment in older people. Integración, 55, 34-42.

[8] Schmid, K., Phelps, E., \& Lerner, R. (2011). Constructing positive futures: Modeling the relationship between adolescents' hopeful future expectations and intentional sell regulation in predicting positive youth development. Journal of Adolescence, 6, 1127-1135.

[9] Muschalla, B., Linden, M., \& Olbrich, D. (2010). The relationship between job-anxiety and trait-anxiety A differential diagnostic investigation with the Job-Anxiety-Scale and the State-Trait A Anxiety Inventory, Journal of Anxiety Disorders, 24(3), 366-371.

[10] National Eye Institute [NEI], (2015). Facts about age-related macular degeneration, Retrieved February 22, 2018 from https://nei.nih.gov/health/maculardegen/armd_facts

[11] Wahl, H.W. (2013). The psychological challenge of late-life vision impairment: Concepts, findings, and practical implications, Journal of Ophthalmology, 11(5), 45-53.

[12] Menon G.J. (2005). Complex visual hallucinations in the visually impaired: A structured history taking approach, Arch Ophthalmol, 3, 349-355.

[13] Posner, M. I., Nissen, M. J. ve Klein, R. M. (1976). Visual dominance: An information processing account of its origins and significance, Psychological Review, 83, 157-171.

[14] Czapinski, J., \& Peters, G. (1991). The onion theory of happiness: Basic concepts and cross-cultural test. In N. Bleichrot \& P.D. Drenth (Eds.), Contemporary issues in cross-cultural psychology (pp. 196-216). Amsterdam: Swets \& Zeitlinger. Francisco, CA, April 18-22, 1995)

[15] Suk, H., Celina, E., Ralph, W., \& Konstantinos, V. (2001). African American College Students Motivation in Education. Paper presented at the Annual Meeting or the American Educational Research. Association Seattle, WA, April 10-14.

[16] Williams, D. (1984). Attitudes towards varieties of Nigerian spoken English. World English's, 3(1), 6-10.

[17] Karrie , J., Craig , K., Brown , J., \& Andrew , B. (2000). Environmental Factors in the Etiology of Anxiety. Neurop psychopharmacology: the fifth generation of progress, 2008. Available from: http://www.acnp.org/g4/GN401000127/Default.htm. Accessed 15 November 2017

[18] Johanson, R.P., \& Vopava, J.R. (1985). Attitude assessment and promotion of college attendance among economically disadvantaged students. Journal of College Student Personnel, 26(A), 339-342.

[19] MacLeod, A., Williams, J.M., \& Bekerian, D.A. (1991). Worry is reasonable: The role of explanations in pessimism about future personal events. Journal of Abnormal Psychology, 100, 478-486.

[20] Schmid, K., Phelps, E., \& Lerner, R. (2011). Constructing positive futures: Modeling the relationship between adolescents' hopeful future expectations and intentional sell regulation in predicting positive youth development. Journal of Adolescence, 6, 1127-1135.

[21] Vukman, K.B., Lorger, T. \& Schmidt, M. (2017). Perceived self-efficacy and social anxiety changes in high school students with learning disabilities (LD) during first year of secondary vocational education. European Journal of Special Needs Education, https://doi.org/10.1080/08856257.2017.1410320

[22] Zhang, W. (2007). Why IS: Understanding Undergraduate Students Intentions to Choose an Information Systems Major. Journal of Information Systems Education, 18(4), 447-458.

[23] Bhaskar, C., \& Soundiraraj, S. (2013). A study on change in the attitude of students towards English language learning. English Language Teaching, 6(5), 111-116.

[24] Oort, F., Lord, K., Verhulst, F., Ormel, J. \& Huizink, A. (2009). The developmental course of anxiety symptoms during adolescence: the TRAILS study. Journal of Child Psychology and Psychiatry, 50(10), 1209-1217.

[25] Price, B. (2009). Differentiating future time perspective and future anxiety as distinct predictors of intimate partner violence. Unpublished doctoral dissertation, Northern Illinois University.

[26] Aderka, I.M., Hofmann, S.G., Nickerson, A., Hermesh, H., Gilboa-Schechtman, E., \& Marom, S. (2012) Functional impairment in social anxiety disorder. Journal of Anxiety Disorders, 26, 393-400.

[27] Mbugua, A.W., \& K'Okul, F., (2013). Psychological Dispositions of Anxiety among Learners with Visual Impairment: A Study of High School for the Blind. International Journal of Humanities and Social Science, 3(17), 67-76.

[28] Novita, S. (2016). Secondary symptoms of dyslexia: a comparison of self-esteem and anxiety profiles of children with and without dyslexia. European Journal of Special Needs Education, 31(2), 279-288.

[29] Rebelo, N., Candeias, A., \& Oliveira, M. (2012). Attitudes toward learning-study of exploratory models about the effects of school level and personal attributes in Portuguese students. Conference name 4th international conference on education and new learning technologies, 2-4 july, Barcelona, Spain, Edulearn 12 proceedings, 2949-2956. 
[30] Femenías, M., \& Sánchez, J.M. (2003). Family satisfaction, psychological well-being and anxiety in couples with children with special educational needs. Siglo Cero, 34(207), 19-28.

[31] Annable, G., Goggin, G., \& Stienstra, D. (2007). Accessibility, disability, and inclusion in information technologies: Introduction. Information Society, 23(3), 145-147.

[32] Fullan, M. (2003). The moral imperative of school leadership. Thousand Oaks: Corwin

[33] Stone, D.L., \& Colella, A. (1996). A Model of factors affecting the treatment of disabled individuals in organizations, Academy of Management Review, 21(2), 352-401.

[34] Bogdan, R.C., \& Biklen, S.K. (2007). Qualitative research for education. London: Pearson.

[35] Merriam, S.B. (1988). Case study research in education: A qualitative approach. San Francisco: Jossey-Bass.

[36] Loeb, S., Dynarski, S., McFarland, D., Morris, P., Reardon, S., \& Reber, S. (2017). Descriptive analysis in education: A guide for researchers. (NCEE 2017-4023). Washington, DC: U.S. Department of Education, Institute of Education Sciences, National Center for Education Evaluation and Regional Assistance.

[37] Evans, J.R., Fletcher, A.E., \& Wormald, R.P.L. (2007). Depression and anxiety in visually impaired older people. Ophthalmology, 114(2), 283-288.

[38] Burmedi, D., Becker, S., Heyl, V., Wahl, H.W. \& Himmelsbach, I. (2002) Emotional and social consequences of age-related low vision. Visual Impairment Research, 4, 47-71.

[39] Kızılaslan, A., \& Sözbilir, M. (2017). Herkes İçin bilim: görme engelli öğrenciler için örnek uygulamalar. Konya: Çizgi Kitabevi

IJERE Vol. 7, No. 2, June 2018: $152-158$ 